\title{
Breast Cancer, Genetic Factors and Methods of Diagnosis
}

\section{ARTICLE INFO}

\section{Article Type}

Review

\section{Authors}

Aleme Mohammadpour ${ }^{1}$, M.Sc Ehsan Jahangirian ${ }^{2}$, M.Sc Tamouchin Moharrami ${ }^{1}, \mathrm{PhD}$ Golnoosh Goljah Rad ${ }^{1}$, PhD Leila Javanparast Sheikhani ${ }^{1}$, M.Sc Sara Taghizadeh ${ }^{1}, \mathrm{PhD}^{*}$

1 Sarem Fertility and Infertility Research Center (SAFIR), Sarem Women's Hospital, Iran University of Medical Sciences (IUMS), Tehran, Iran

${ }^{2}$ National Institutes of Genetic Engineering and Biotechnology, Tehran, Iran

*Corresponding Author

Address: Sarem Women Hospital, Basij Square, Phase 3, EkbatanTown, Tehran, Iran. Postal code: 1396956111 Phone: +98 (21) 44670888 Fax: +98 (21) 44670432 s.taghizadeh@sarem.org

\section{Article History}

Received: September 18, 2019 Accepted: December 05, 2019 e Published: January 03, 2021

\begin{abstract}
Background and Aims: Breast cancer is the most common cancer in women. Screening, early detection, and prediction of the susceptibility are very important in drug response and choosing the appropriate treatment. Due to the limitations of conventional screening methods, such as low sensitivity and specificity, pain and anxiety, and radiation hazards of imaging techniques, use of biomarkers that can overcome these limitations would be important. Tumor markers (Protein and nucleic acid) are the most important molecular markers involved in cancer progression. About half of all hereditary breast cancers are caused by germline mutation in tumor suppressor genes and genes involved in mismatch repair, cell cycle control, steroid hormone metabolism, and cell signaling. Therefore, quantitative study of these genes can be used as a possible indicator in early detection of breast cancer. In this study, we introduce the genes involved in inherited breast cancer and the role of the main molecular techniques of its diagnosis in comparison with traditional methods.

Conclusion: Various techniques such as IHC, FISH, CGH, Micro array, etc. and Molecular techniques such as RT-PCR, MLPA, QPCR, and NGS are used to measure tumor markers. Today, these techniques promise to improve diagnosis and help to select an appropriate treatment for patients and find specific mutations such as BRCA1 and BRCA2, HER3, etc.
\end{abstract}

Keywords: Breast Cancer, Tumor markers, Diagnosis, Prognosis, Genetics, Test

Copyright(C) 2020, ASP Ins. This open-access article is published under the terms of the Creative Commons Attribution-Noncommercial 4.0 International License which permits Share (copy and distribute the material in any medium or format) and Adapt (remix, transform, and build 


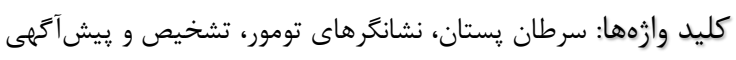

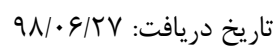

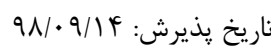

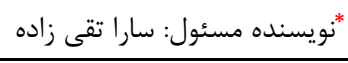

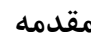

سرطان يك مشكل عمده بهداشتى و عامل ؟باء مركى و مير در سراسر

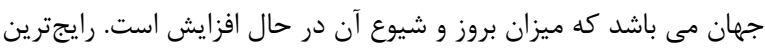

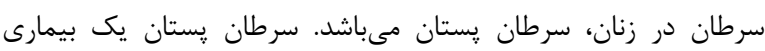

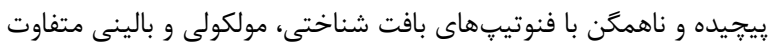

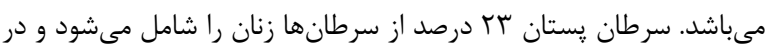

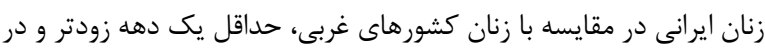

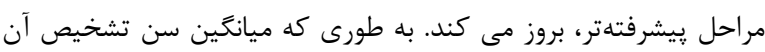

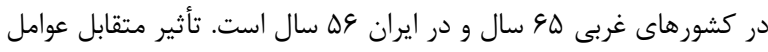

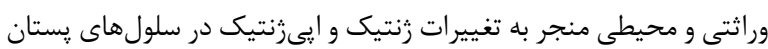

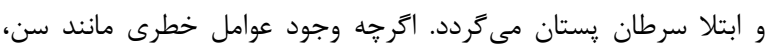

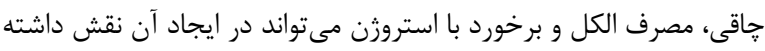

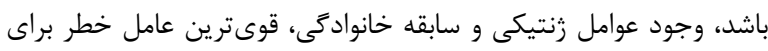

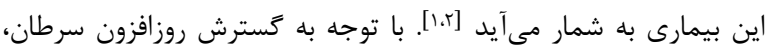

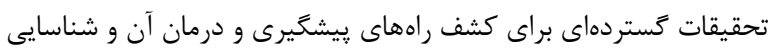

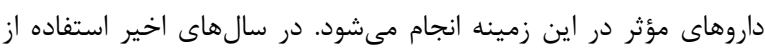

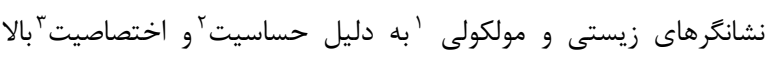

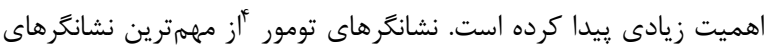

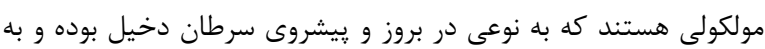

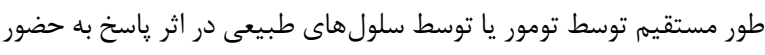

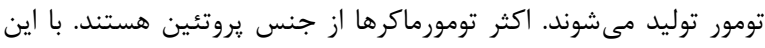

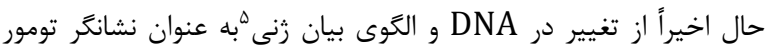

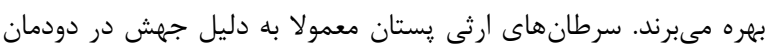

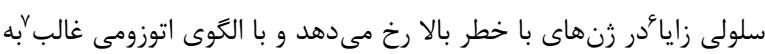

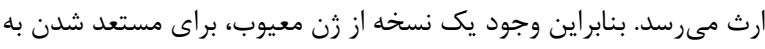

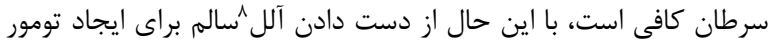

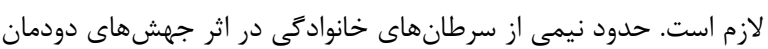

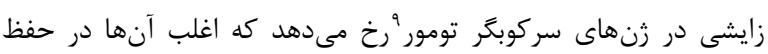

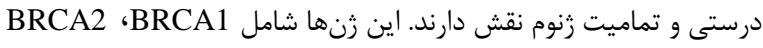

Germline Cell Autosomal Dominant Inheritance Allele ${ }^{\wedge}$ Tumor Suppressor Genes (TSGs) ${ }^{\natural}$

\section{سرطان سينه، عوامل زنتيكى موثر و روشهاى تشخيص آن}

عالمه محمديور '، احسان جهانگيريان' ، تموجين محرمى ل ، كلنوش گلجاه

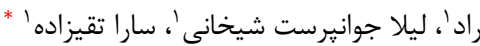

' مركز تحقيقات بارورى و نابارورى صارم، بيمارستان فوق تخصصى صارم،

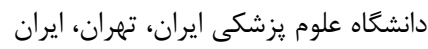

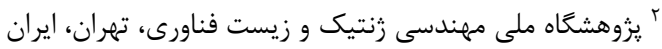

جكيده زمينه ها و اهداف: سرطان يستان، رايج ترين سرطان در زنان است.

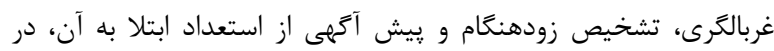

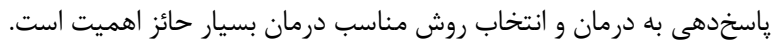

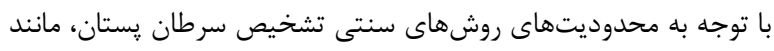

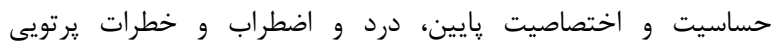

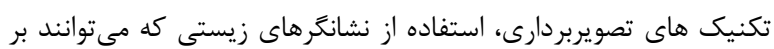

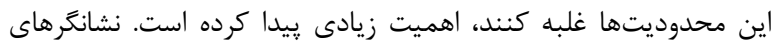

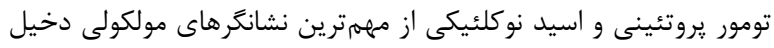

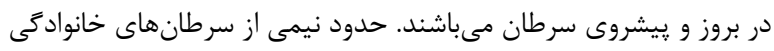

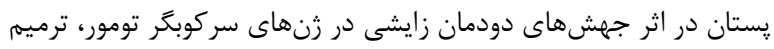

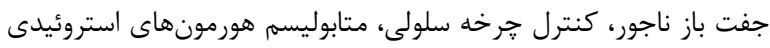

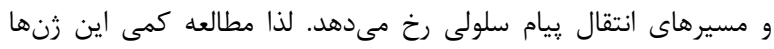

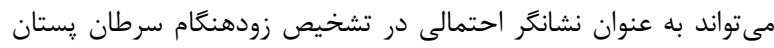

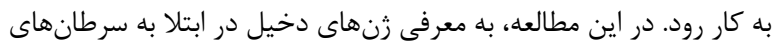

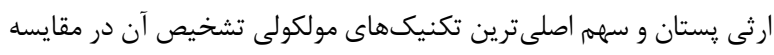
با روشهاى سنتى مى يردازيم.

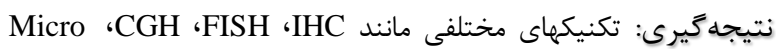

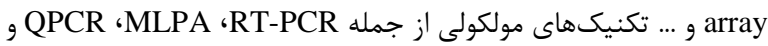
جهS

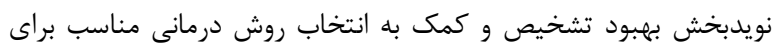

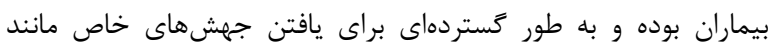
و و و BER3 ، BRCA2 
زنهاى دخيل در ابتلا به سرطانهاى ارثى زنان و سهمم اصلىترين

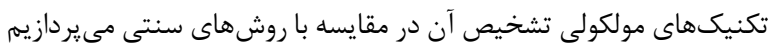

\section{طبقه بندى سرطان يستان}

يارامترهاى تشخيص مورفولوزيكى سرطان يستان شامل شئل اندازه و درجه

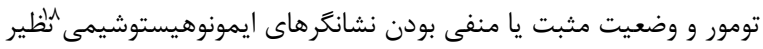

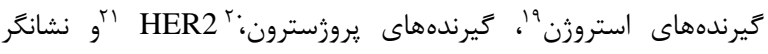

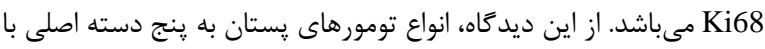

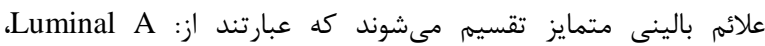
HER2 Over- ،Normal-Like ،Basal-Like ،Luminal B

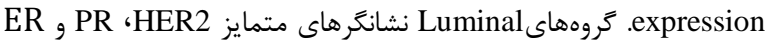

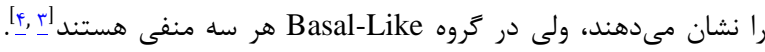

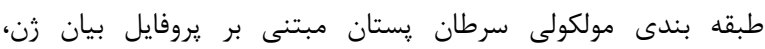

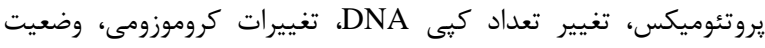

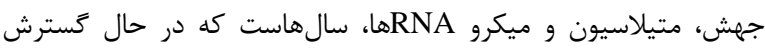

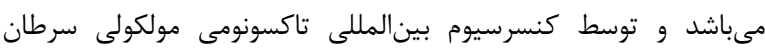

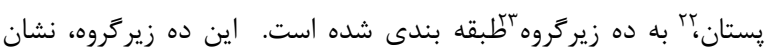

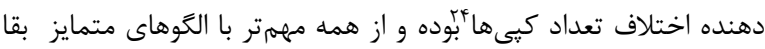

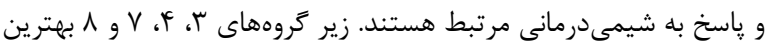

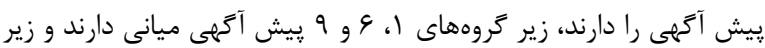

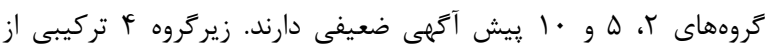

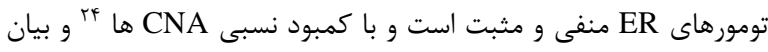
زن منعكس كننده فعاليت ايمنى شناخته مى شود. اكثر تومورهاى

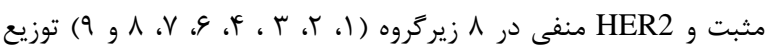

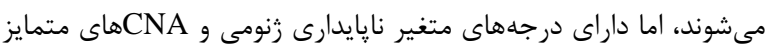

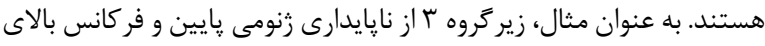

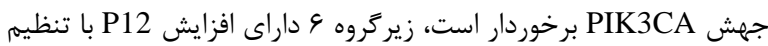

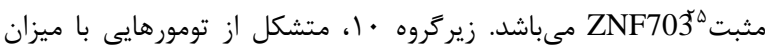

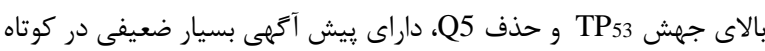

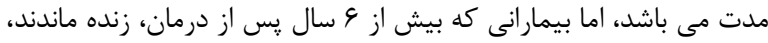

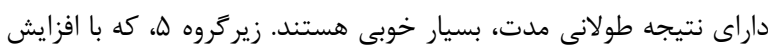

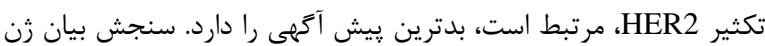

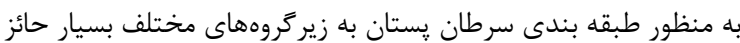

Estrogen Receptor (ER) ${ }^{19}$ Progesterone Receptor (PR) ${ }^{r}$ Human Epidermal Growth Factor Receptor 2 (HER2) ${ }^{r}$ Molecular Taxonomy of Breast Cancer International ${ }^{r}$ Consortium (METABRIC) IntClust ${ }^{r}$ Copy Number Alterations (CNAs) ${ }^{r s}$ Upregulation $^{\text {ro }}$
PRIP1، PALB2 ، NBS1 RAD50 PTEN

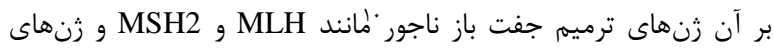
دخيل در كنترل خرخه سلولى، متابوليسم هورمونهاى استروئيدى و

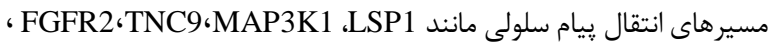

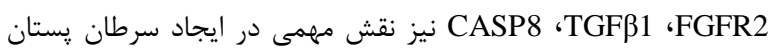

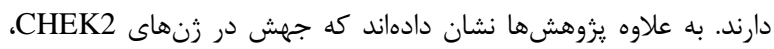

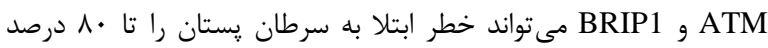

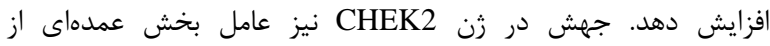

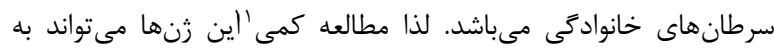

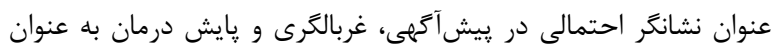

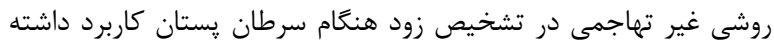

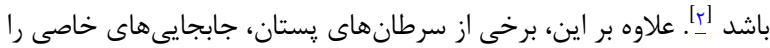

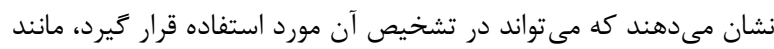

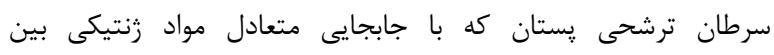

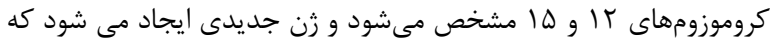

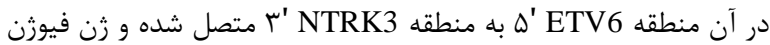
ETV6-NTRK3

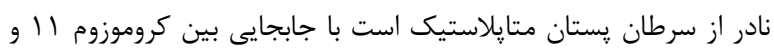

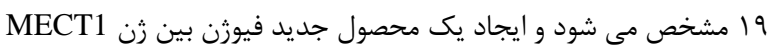

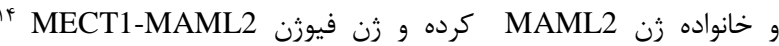

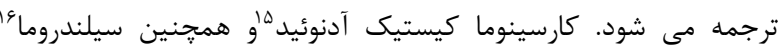

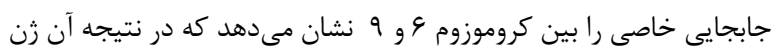

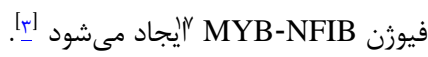

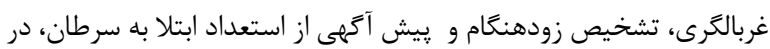

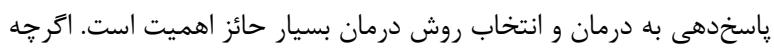

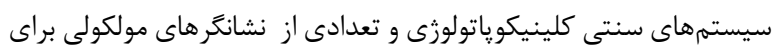

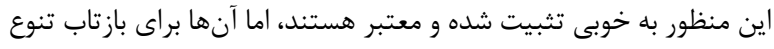

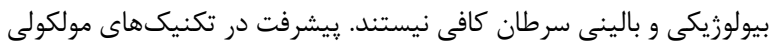

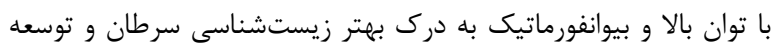

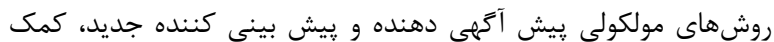

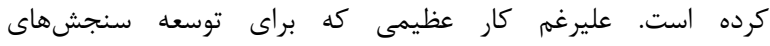

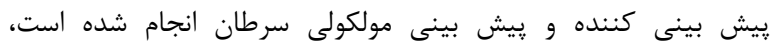

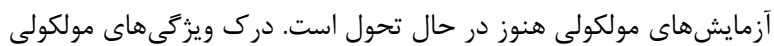

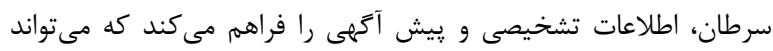

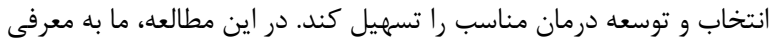

DNA Mismatch Repair (MMR) Genes Quantitative Study ETV6-NTRK3 Gene Fusion Mucoepidermoid Carcinoma MECT1-MAML2 Gene Fusion ' Adenoid Cystic Carcinoma (ACC) ${ }^{10}$ Cylindroma

MYB-NFIB Gene Fusion ' Immunohistochemistry (IHC) '

دانشنامه صارم در طب بارورى 
ثن BRCA2 به عنوان دومين زن يرنفوذ است كه روى كروموزوم

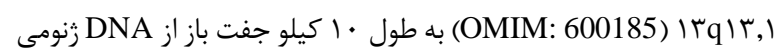

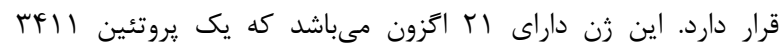

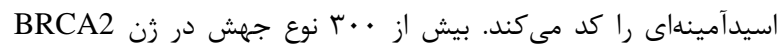

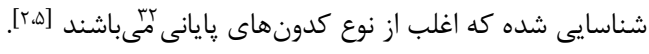

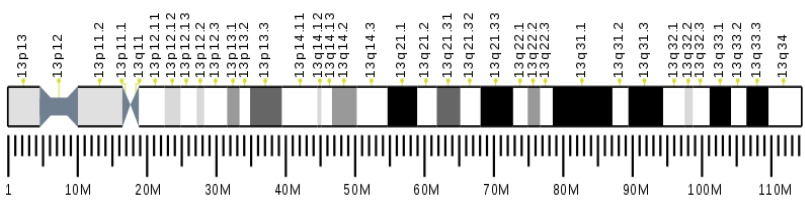

\section{PTEN}

زن PTEN تبّوليد كننده تيـروزين فـسفاتازى است كه نقش سركوبخرى

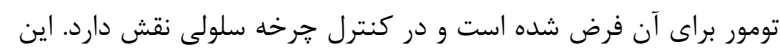

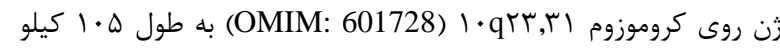

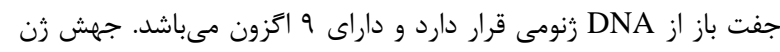
PTEN

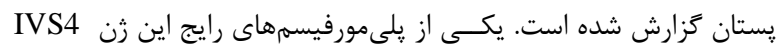

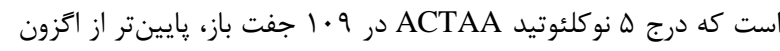

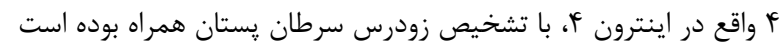

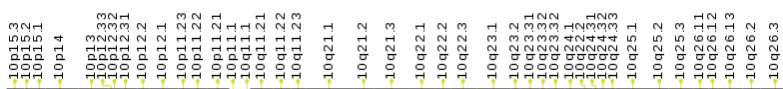

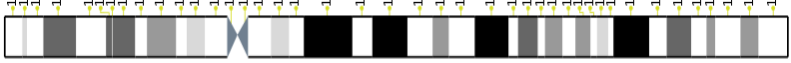 |||||||||||||||||||||||||||||||||||||||||||||||||||||||||||||||||||||||||||||||||||||||||||||||||||||||||||||||||||||||||||||||||||||||| $\mid$}

HER2 يكى از \& عضو خانواده تيروزين كيناز غشايى (OMIM: 164870) HER2

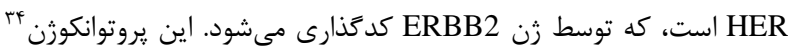

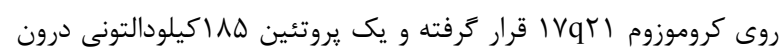

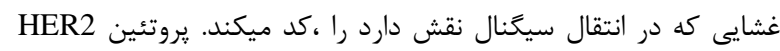

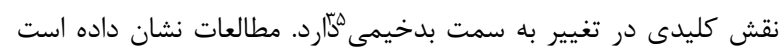

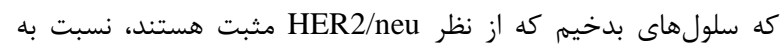

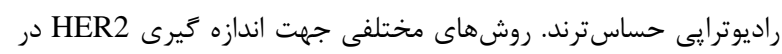

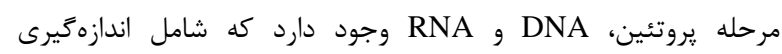

Stop Codon ${ }^{r r}$ Phosphatase And Tensin Homolog rr Proto-oncogene ${ }^{r \varepsilon}$ Malignant Transformation ${ }^{\text {ro }}$
اهميت. زيرا سرطان هاى مربوط به زيركروههاى مختلف پاسخهاى متفاوتى

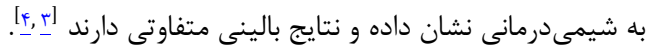

زنهاى كليدى موثر در ايجاد سرطان يستان :BRCA2 , BRCA1

BRCA2 مستعدترين و شناخته شده ترين زنهاى ابتلا به و BRCA1

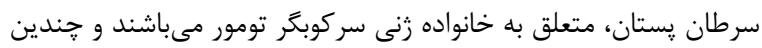

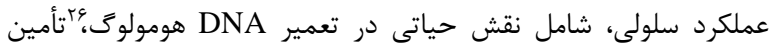

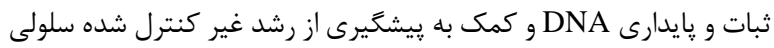

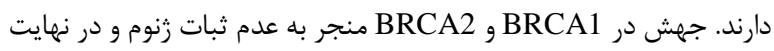

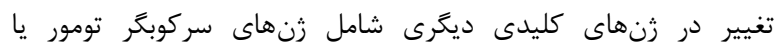

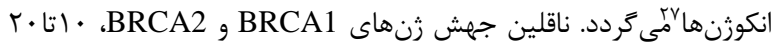

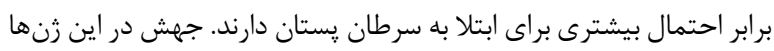

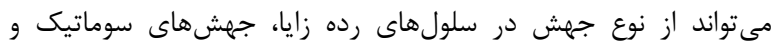

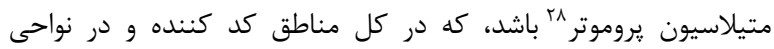

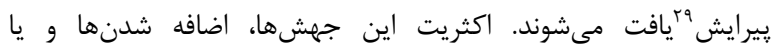

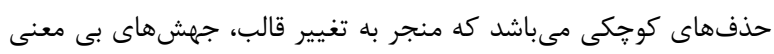

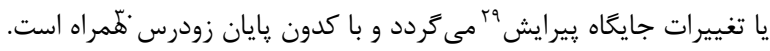

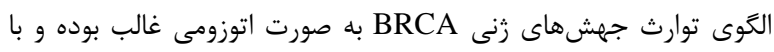

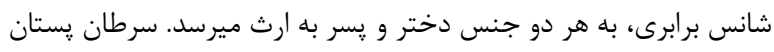

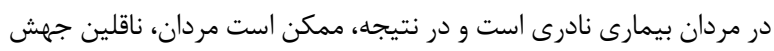

رن BRCA1 نخستين زن ثرنفوذ عامل سرطان مىباشد كه جهش در آن

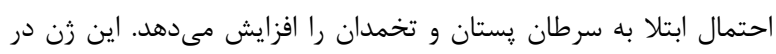

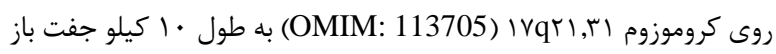

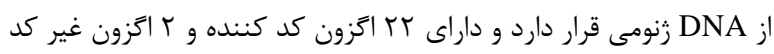

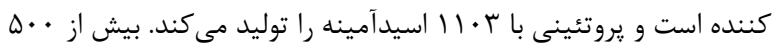
نوع جهش متفاوت در اين زن شناسايى شده كه شامل جايكزينى بهاى تك نوكلئوتيدى! نحذف و الحاق مى باشد.

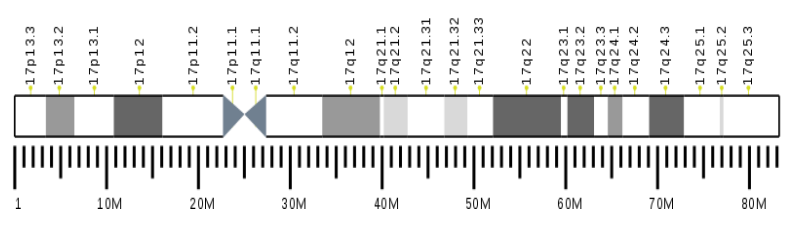

Homologous DNA Repair
Oncogene
${ }^{r+}$
Promoter Methylation
Splicing
${ }^{r q}$
Premature Stop Codon
${ }^{r}$

دانشنامه صارم در طب بارورى 
شمار زيادى از مطالعات همراهى گسترده زنومى، ^جايخاههاى خطر مرتبط

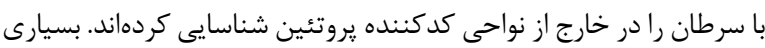

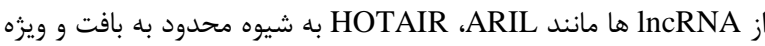

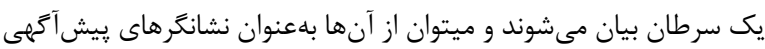

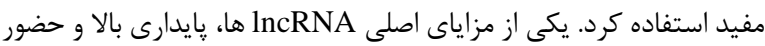

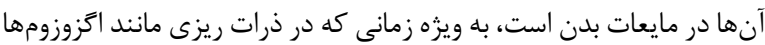

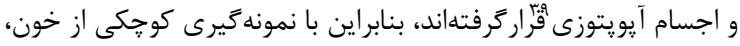

ادرار و يا بزاق و در ادامه با بهرهگيرى از روش Real time-PCR مى مقتوان

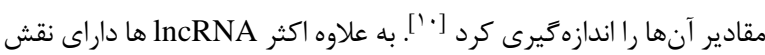

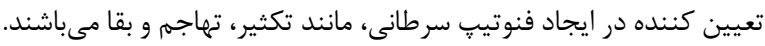

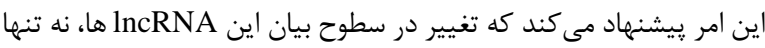

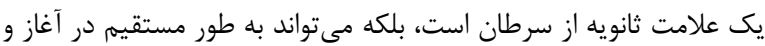

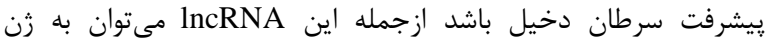

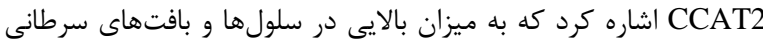

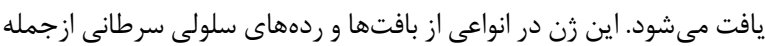

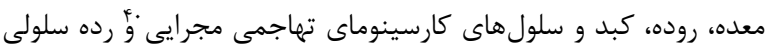

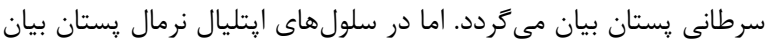

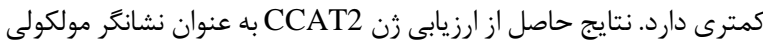

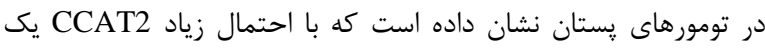

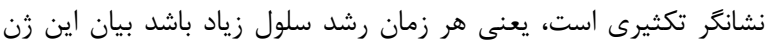

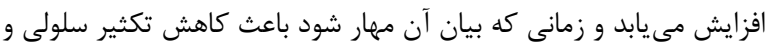

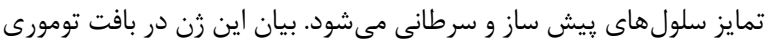

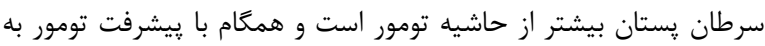

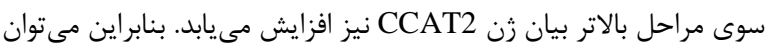

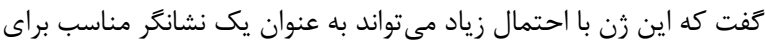

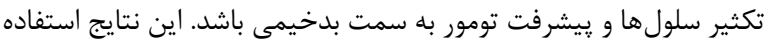

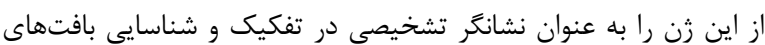

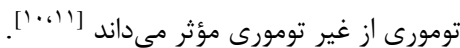

\section{MicroRNA (miRNA)}

miRNA

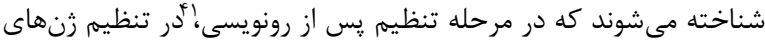

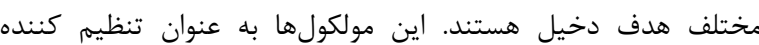

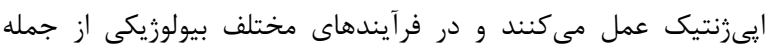

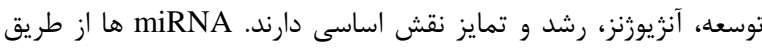
هدف قرار دادن انواع مسيرهاى سلولى و مولكولى مى توانند در ياتوزنز

Apoptotic Bodies ${ }^{r}$ Invasive ductal carcinoma (IDC) « Post-transcriptional Gene Regulation "
ايمونوهيستوشيمى گيرنده HER2، استفاده از يافتن مضاعف شدكى زنها

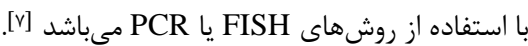

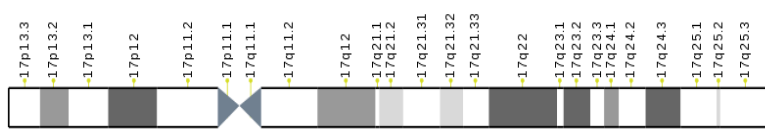

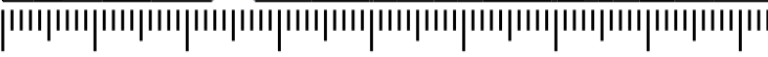

HER3

HER يكى از يروتئينهاى متصل به غشا متعلق به خانواده HER3

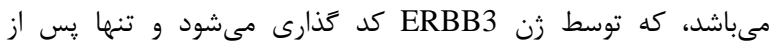

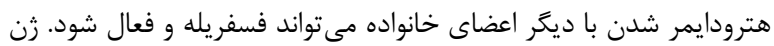

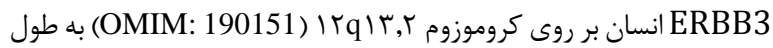

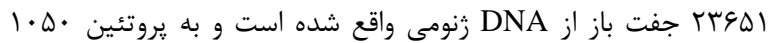

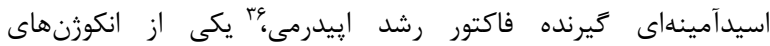

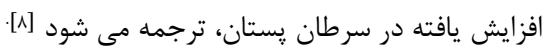

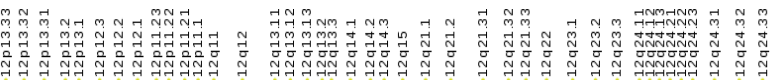

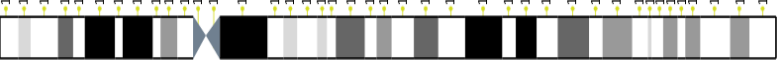
||||||||||||||||||||||||||||||||||||||||||||||||||||||||||||||||||||||||||||||||||||||||||||||||||||||||||||||||||||||||||||||||||||||||||||||

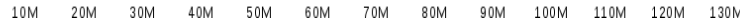

\section{Ki-67}

يروتئين ديخرى كه نقش مهمى در ياتوزنز سرطان يستان دارد. اين يروتئين

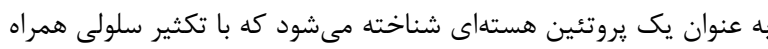

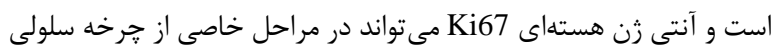

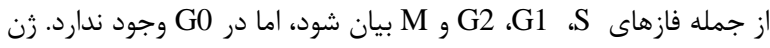

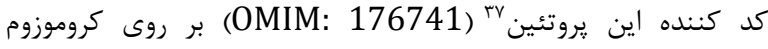

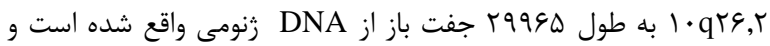

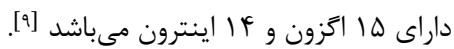

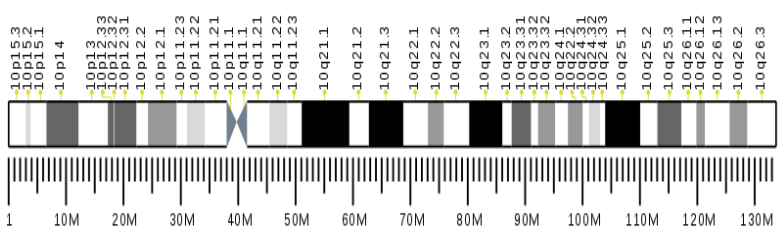

long non-coding RNAs (IncRNAs)

Epidermal Growth Factor Receptor ${ }^{r}$ MKI67 ${ }^{r}$ Genome-Wide Association Studies (GWAS) ${ }^{r \wedge}$ 


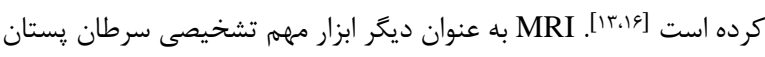

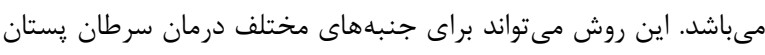

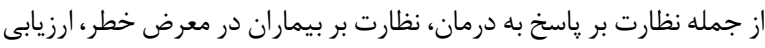

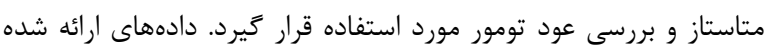

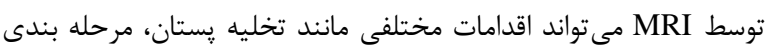

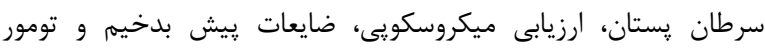

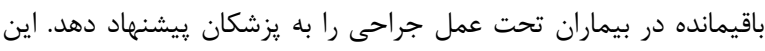

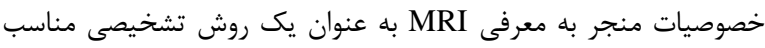

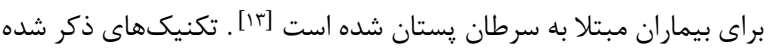

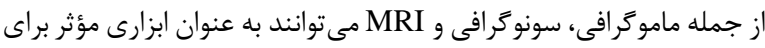

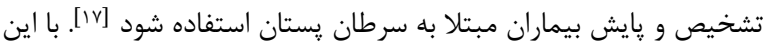

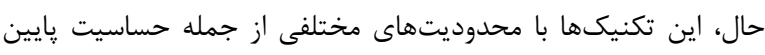

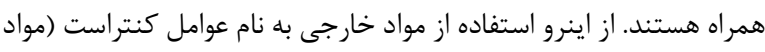

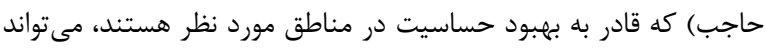

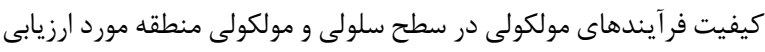

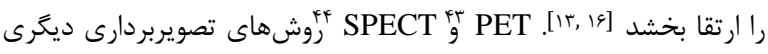

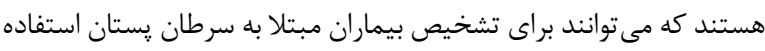

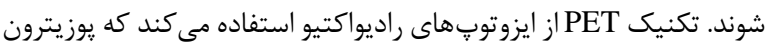

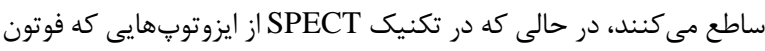

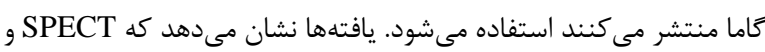

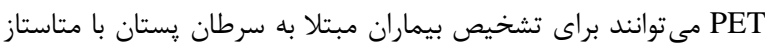

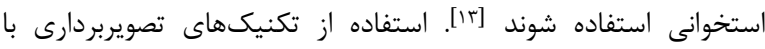

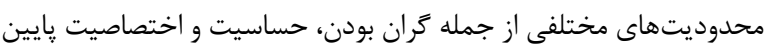

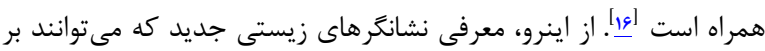

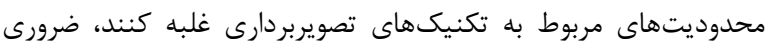

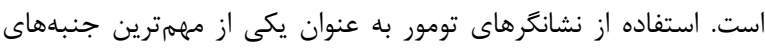

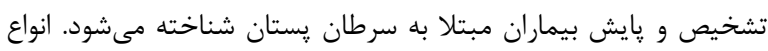

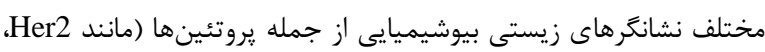

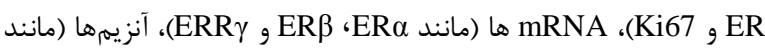

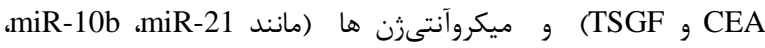

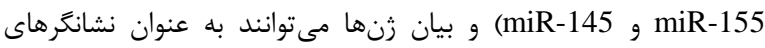

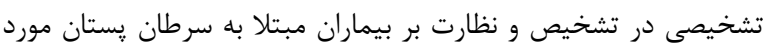

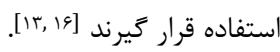

تكنيكهاى جديد اندازهكيرى نشانكر هاى تومور

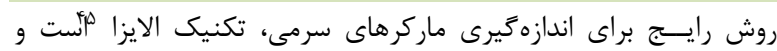

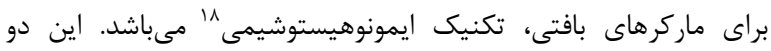

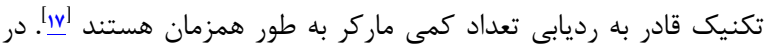

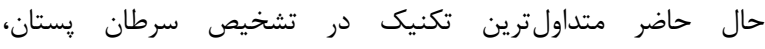

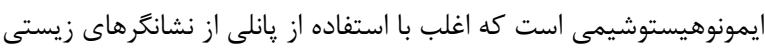

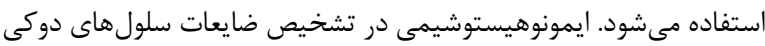

Single-Photon Emission Computed Tomography (SPECT) « Enzyme-Linked Immunosorbent Assay (ELISA) ؛o
سرطان پستان نقش داشته باشند و مىتواند با بدخيمى تومور، پاسخ به

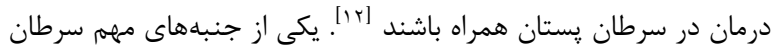

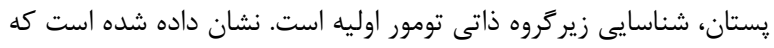

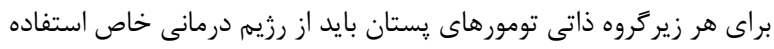

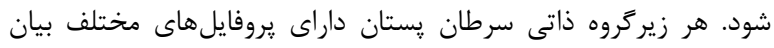
miRNA بيان miRNA به عنوان كانديداى مؤثر براى تشخيص و و إيش بيثر بيماران

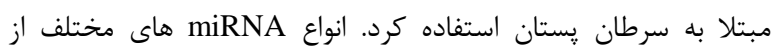

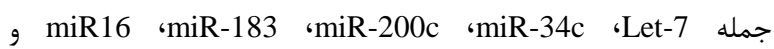
miR-203 مى تواند در مراحل مختلف سرطان يستان، از طريق تاثير گذارى

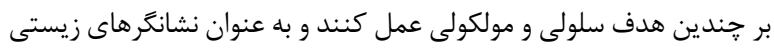
تشخيصى براى سرطان پستان بكار روند [r.

مكانيسمهاى ايبىرنتيكى

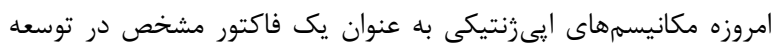

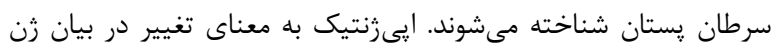

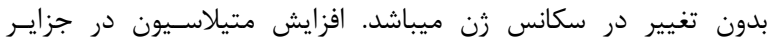
CpG

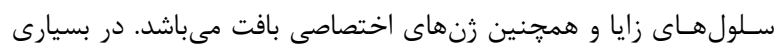

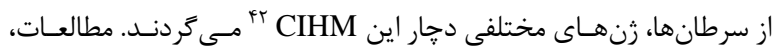

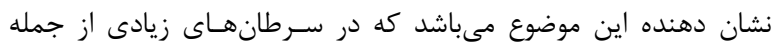

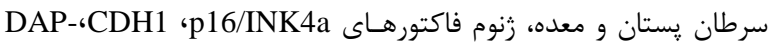
Kinase p14/ARF با افزايش متيلاسيون همراه بوده، كـهـ اين فاكتورها

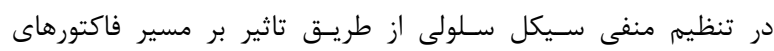

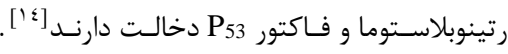

\section{روشهاى متداول تشخيص سرطان يستان}

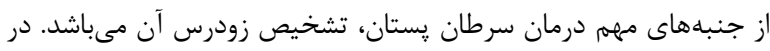

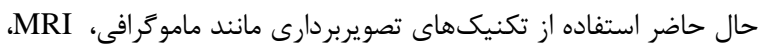
يكى از رويكردهاى اصلى براى تشخيص و ارزيابى SPECT CT PET

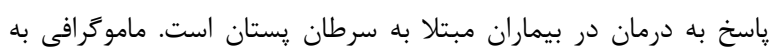

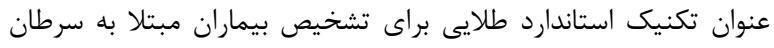

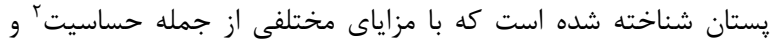

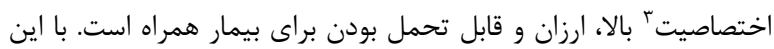

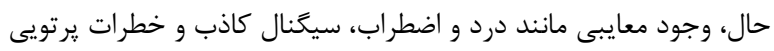

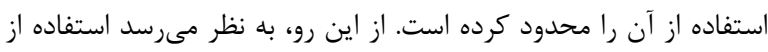

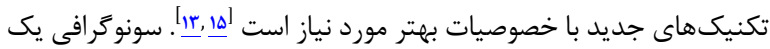

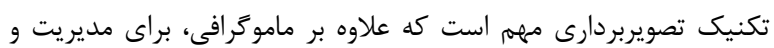

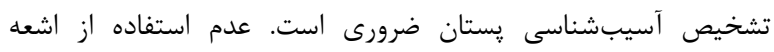

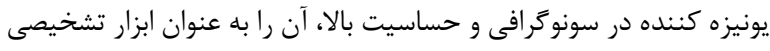

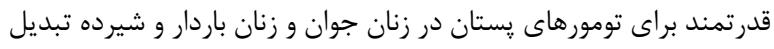

CpG Island Hypermethylation (CIHM) ${ }^{\varepsilon r}$ Positron Emission Tomography (PET) ${ }^{\text {\&r }}$ 
تومورها را به درمانهاى اختصاصى ارزيابى كند. در حالى كه اين روش قادر

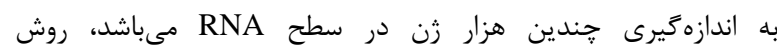

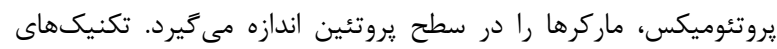

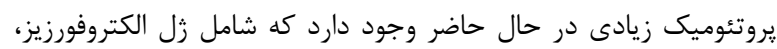

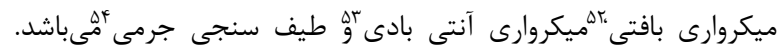

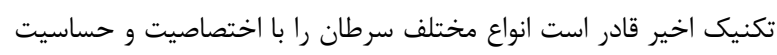

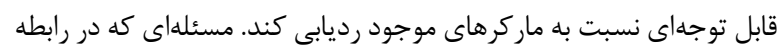

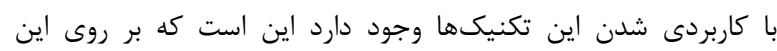

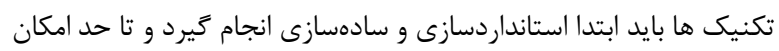

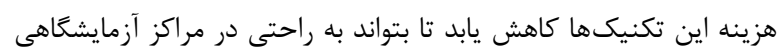

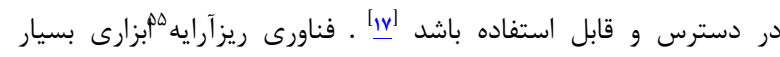

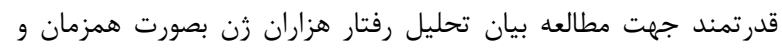

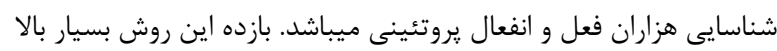

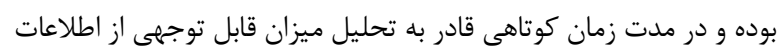

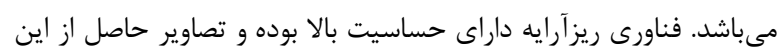

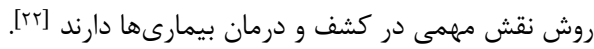

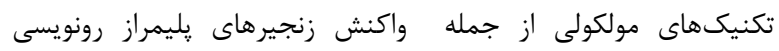

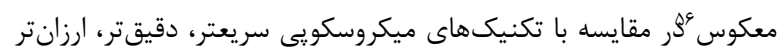

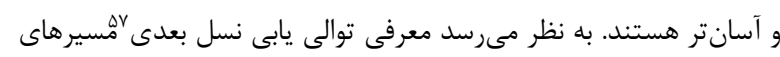

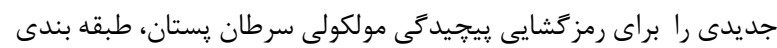

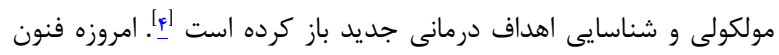

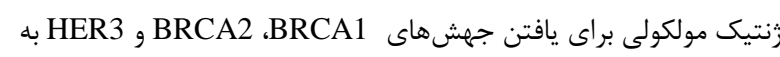

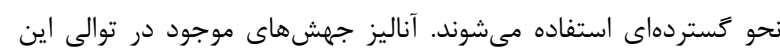

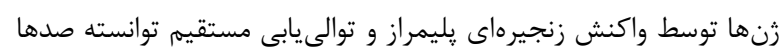

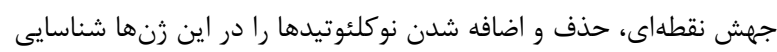

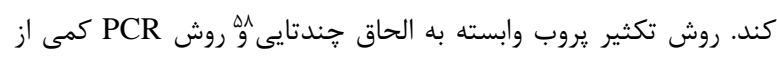

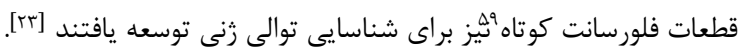

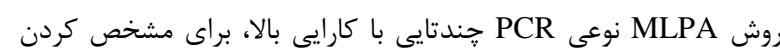

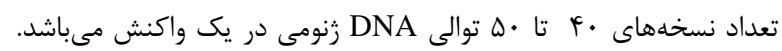

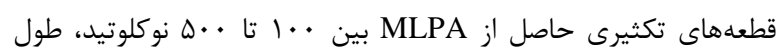
دارند كه قابل جداسازى و كمى سازى به به وسيله الكتروفورز مويين هستيند

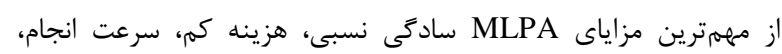

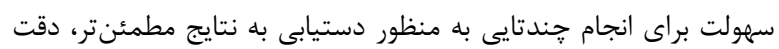

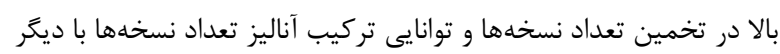

\footnotetext{
Mass Spectrometry ${ }^{\circ}$ Microarray ${ }^{\circ 0}$

Reverse Transcription Polymerase Chain Reaction (RT- ${ }^{\circ}$ (RCR)

Next-Generation Sequencing (NGS) ${ }^{\circ v}$

Multiplex Ligation-Dependent Probe Amplification ${ }^{\circ}$ quantitative Polymerase Chain Reaction (qPCR) ${ }^{\circ 9}$ (MLPA)
}

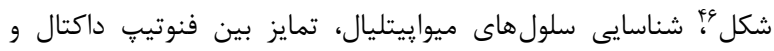

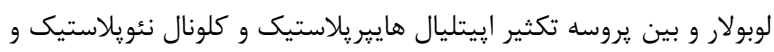

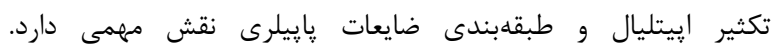

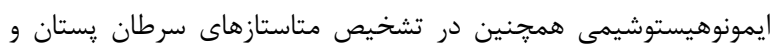

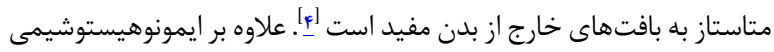

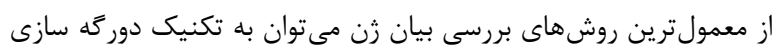

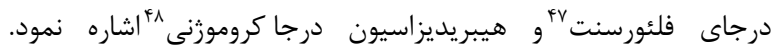

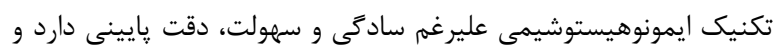
نتايج مثبت كاذب زيادى ارائه مىدهد و تست

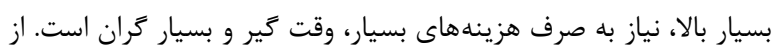

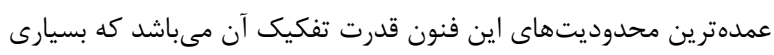

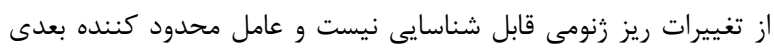

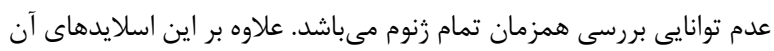

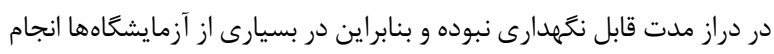
يذير نمىباشد [11 [19].

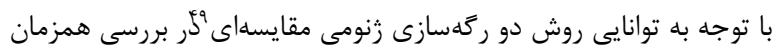

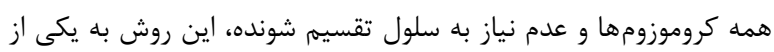

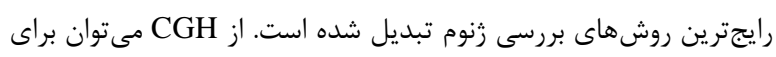

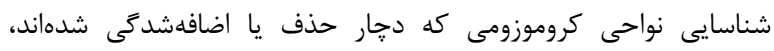

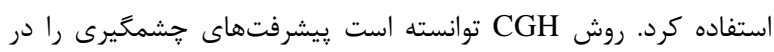

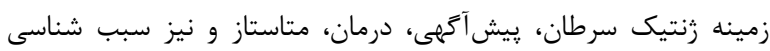

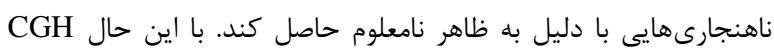

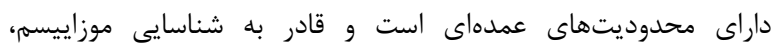

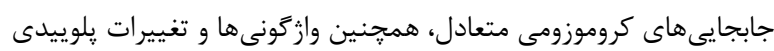

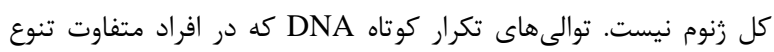

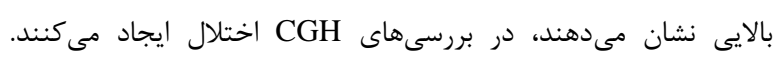

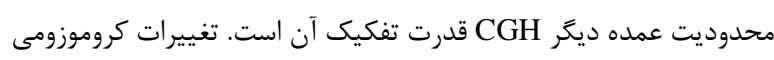

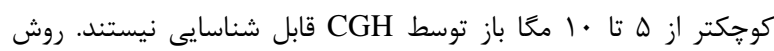

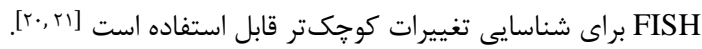

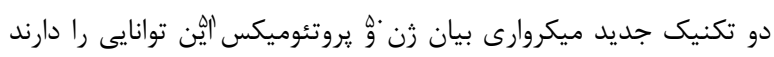

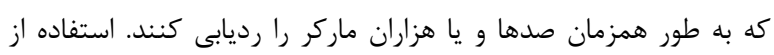

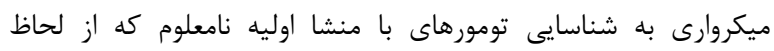

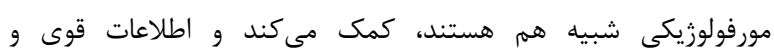

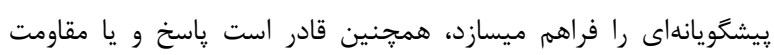

Spindle-Shaped Cells $\$$ Fluorescence In-Situ Hybridization (FISH) ${ }^{\varepsilon v}$ Chromogenic In-Situ Hybridization (CISH) sA Comparative Genomic Hybridization (CGH) ${ }^{\circ 9}$ Microarray-Based Gene Expression ${ }^{\circ}$. Proteomics ${ }^{\circ 1}$ Tissue Microarray or Antibody Microarray or

$$
\text { دانشنامه صارم در طب بارورى }
$$

دوره Fا، شماره أ، زمستان 1وسا 


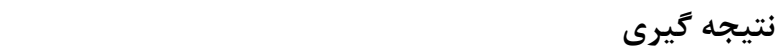

سرطان يستان يكى از سرطانهاى مهرم در بين زنان است كه به عنوان

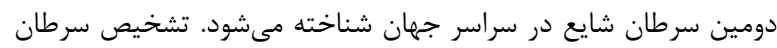

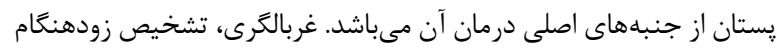

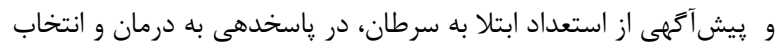

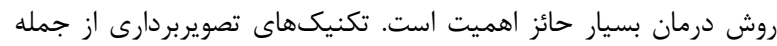

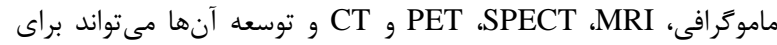

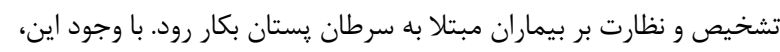

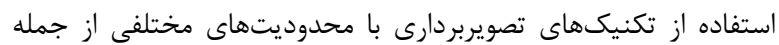

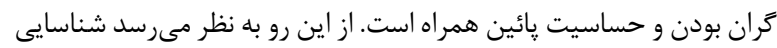

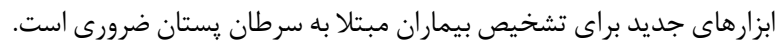

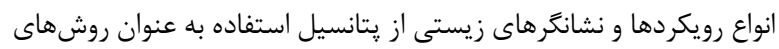

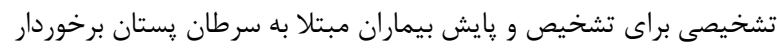

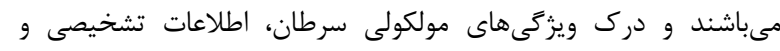

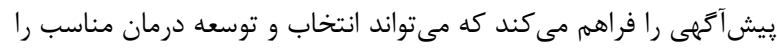

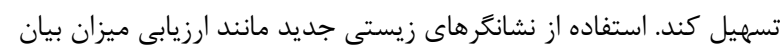

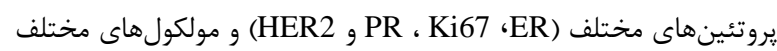

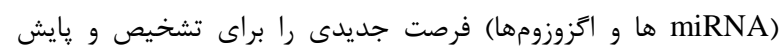

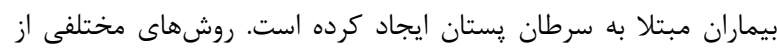
جمله ELISA، Microarray ،CGH ، CISH ، IHC ، جهectrometry

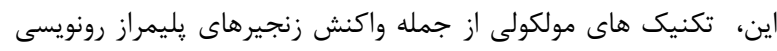

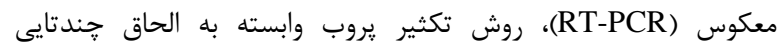

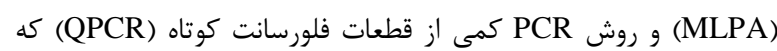

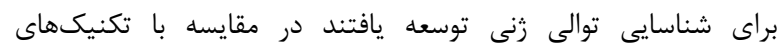

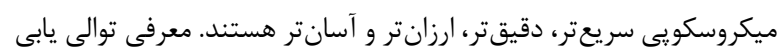

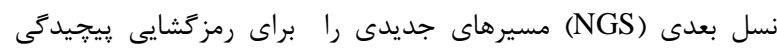

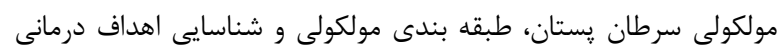

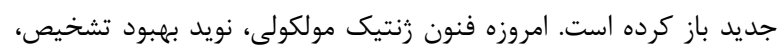

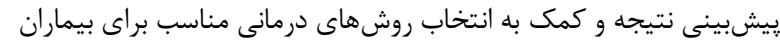

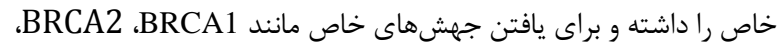
HER3 و غيره، به نحو گستر دهاى استفاده مىشوند.

تشكر و قدردانى: بدينوسيله از كليه متخصصان و يزشكانى كه بيماران

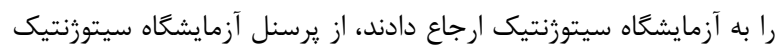
بيمارستان صارم و خانواده هاى ارجاعى كمال تشكر و قدردانى را داريمه.

تاييديه اخلاقى: اين طرح مورد تاييد كميته اخلاق (IEC) مركز تحقيقات بارورى و نابارورى صارم قرار كرفت احتين مورد تايد

Recurrence Odds Ratio (ROR) ${ }^{7}$
روشها مىباشد. در مقايسه با PCR جندتايى استاندارد، تنها يك جفت

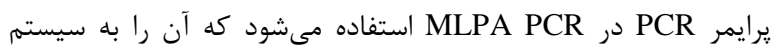

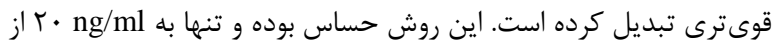
DNA

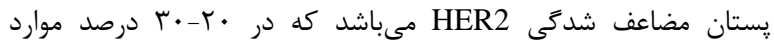

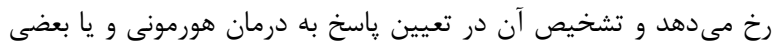

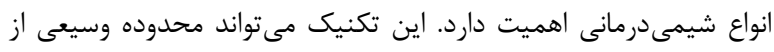

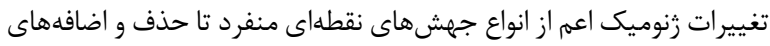

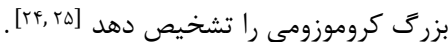

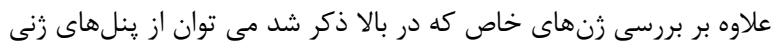

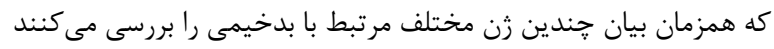

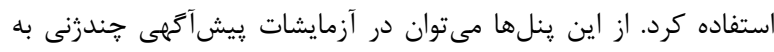

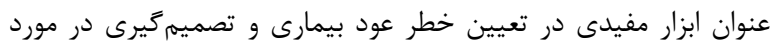

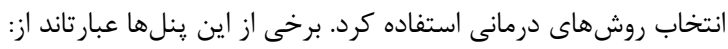
Oncotype Dx

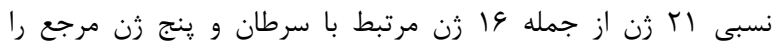

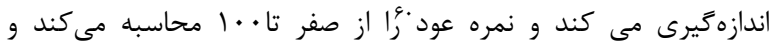

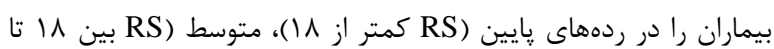

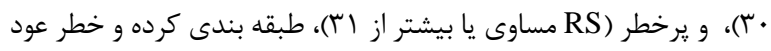

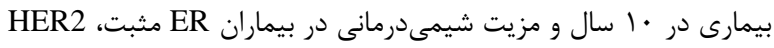

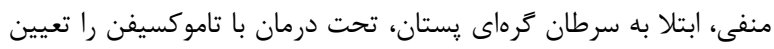
مى كند [re]

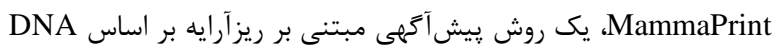

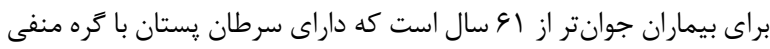

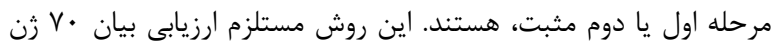

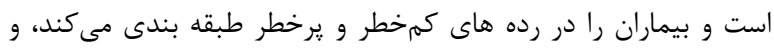

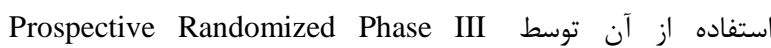
MINDACT Trial Prosigna NanoString

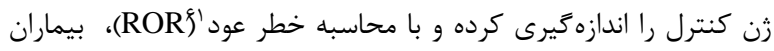

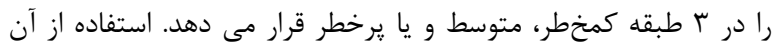

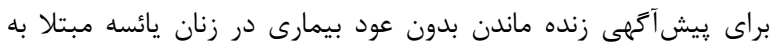

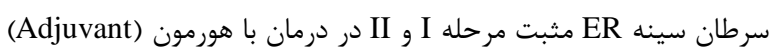
تأييد شده است [عr]. تndoPredict

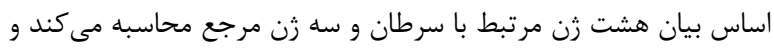

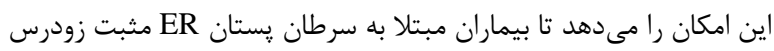

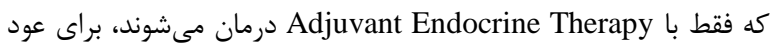

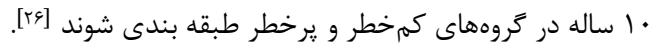

Recurrence Score (RS) ${ }^{7}$ 
Majallah-i Danishgah-i Ulum-i Pizishki-i Fasa 2018.7(4)

12. Kurozumi, S., et al., Recent trends in microRNA research into breast cancer with particular focus on the associations between microRNAs and intrinsic subtypes. Journal of human genetics, 2017. 62(1): p. 15-24.

13. Jafari, S.H., et al., Breast cancer diagnosis: Imaging techniques and biochemical markers. Journal of cellular physiology, 2018. 233(7): p. 5200-5213.

14. Pasculli, B., R. Barbano, and P. Parrella. Epigenetics of breast cancer: Biology and clinical implication in the era of precision medicine. in Seminars in cancer biology. 2018. Elsevier.

15. Wellings, E., L. Vassiliades, and R. Abdalla, Breast cancer screening for high-risk patients of different ages and risk-which modality is most effective? Cureus, 2016. 8(12).

16. Alcantara, D., et al., Molecular imaging of breast cancer: present and future directions. Frontiers in chemistry, 2014. 2: p. 112.

Vا. . جاووشى و همكاران ماركرهاى سرطانى در يك نناه. مجله

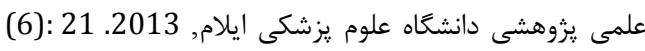

p. $143-159$

18. Nguyen, H.T., et al., Breast cancer HER2 analysis by extra-short incubation microfluidics-assisted fluorescence in situ hybridization (ESIMA FISH). Microelectronic Engineering, 2018. 189: p. 3338.

19. نياركى, ط. و همكاران بررسى زن HER3 به روش-RT

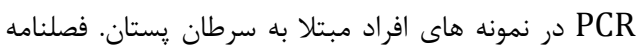

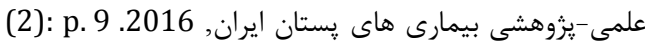
60-65.

20. Fiegler, H., et al., High resolution array-CGH analysis of single cells. Nucleic acids research, 2007. 35(3): p. e15-e15.

21. Gerami, P., et al., Fluorescence in situ hybridization (FISH) as an ancillary diagnostic tool in the diagnosis of melanoma. The American journal of surgical pathology, 2009. 33(8): p. 1146-1156.

22. Heller, M.J., DNA microarray technology: devices, systems, and applications. Annual review of biomedical engineering, 2002. 4(1): p. 129-153.

23. Schouten, J.P., et al., Relative quantification of 40 nucleic acid sequences by multiplex ligationdependent probe amplification. Nucleic acids research, 2002. 30(12): p. e57-e57.

$$
\text { منارض منافع: در اين مطالعه تعارض منافع وجود نداشت. }
$$

منابع

1. Manoochehri, J., A. Abdollahi, and A. Tajik, EPIDEMIOLOGICAL STUDY OF BREAST TUMORS IN IRANIAN PATIENTS. 2018.

r

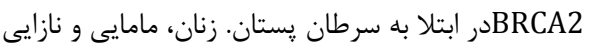

ايران, Journal of Obstetrics Gynecology and Infertility, 2016. 19.

3. Mukherjee, A., et al., Associations between genomic stratification of breast cancer and centrally reviewed tumour pathology in the METABRIC cohort. npj Breast Cancer, 2018. 4(1): p. 5.

4. Rakha, E.A. and A.R. Green, Molecular classification of breast cancer: what the pathologist needs to know. Pathology, 2017. 49(2): p. 111-119.

5. Godet, I. and D.M. Gilkes, BRCA1 and BRCA2 mutations and treatment strategies for breast cancer. Integrative cancer science and therapeutics, 2017. 4(1).

6. Smith, E.L., C.S. Kappler, and S.P. Ethier, Role of PTEN loss in basal-like 2 triple negative breast cancer, 2017, AACR.

7. Hsu, J.L. and M.-C. Hung, The role of HER2, EGFR, and other receptor tyrosine kinases in breast cancer. Cancer and Metastasis Reviews, 2016. 35(4): p. 575-588.

8. Mishra, R., et al. Role of her3 signaling pathways in er+ and her2+ breast cancers. in Cancer Research. 2019. AMER ASSOC CANCER RESEARCH 615 CHESTNUT ST, 17TH FLOOR, PHILADELPHIA, PA ....

9. Li, L.T., et al., Ki67 is a promising molecular target in the diagnosis of cancer. Molecular medicine reports, 2015. 11(3): p. 1566-1572.

10. Juan-Larrea, N., et al., The role of long noncoding RNAs in breast cancer dissemination to the brain. 2018.

11. زاده, ك. و همكاران بر رسى بيان زن CCAT2 به عنوان

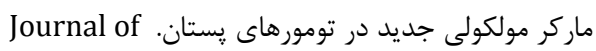
Fasa University of Medical Sciences/ 
24. Kozlowski, P., A.J. Jasinska, and D.J. Kwiatkowski, New applications and developments in the use of multiplex ligation-dependent probe amplification. Electrophoresis, 2008. 29(23): p. 4627-4636.

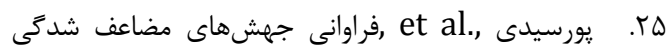

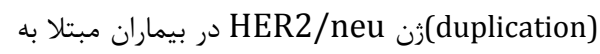
سرطان پِتان با استفاده از روش .MLPA دانشخاه علوم

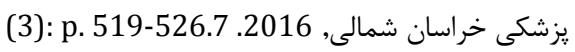

26. Pareja, F., C. Marchiò, and J.S. Reis-Filho, Molecular diagnosis in breast cancer. Diagnostic Histopathology, 2018. 24(2): p. 71-82. 